\title{
Sob o céu que nos protege \\ (ensaio visual)
}

\author{
Under the Sky that Protects Us \\ (visual essay)
}

\section{Bajo el cielo que nos protege \\ (ensayo visual)}

Daniel Moreira

http://dx.doi.org/10.22409/poiesis.1932.11-20

RESUMO: Sob o céu que nos protege é fruto do convívio do artista com moradores de um conjunto de nove ocupações urbanas denominado Vale Das Ocupações na cidade de Belo Horizonte, Minas Gerais.

PALAVRAS-CHAVE: ocupações urbanas; fotografia; arte contemporânea

\footnotetext{
* Daniel Moreira é fotógrafo e artista visual. Formado em comunicação pelo Centro Universitário Newton Paiva, busca o diálogo entre situações documentais e as artes visuais. Utilizando o vídeo e a fotografia como linguagem, se dedica à investigação dos sentimentos e das condições humanas através de um olhar que humaniza o mundo em suas relações diversas com o imaginário, com o ser humano e o consumo. Vive e trabalha em Belo Horizonte. Email: contato@danielmoreira.art.br
} 
ABSTRACT: Under the Sky that Protects Us is the product of the artist's close association with residents of a set of nine urban occupations called Vale das Ocupações in the city of Belo Horizonte, Minas Gerais.

KEYWORDS: urban occupations; photography; contemporary art

RESUMEN: Bajo el cielo que nos protege es producto de la convivencia del artista con moradores de un conjunto de nueve ocupaciones urbanas denominado Valle de las Ocupaciones en la ciudad de Belo Horizonte, Minas Gerais.

PALABRAS CLAVE: ocupaciones urbanas; fotografía; arte contemporáneo

As obras apresentadas neste ensaio estiveram exposta

em uma instalação realizada pelo artista no Palácio Das Artes,

Belo Horizonte, entre junho e agosto de 2018.

Como citar: MOREIRA, Daniel. Sob o céu que nos protege (ensaio visual).

Poiésis, Niterói, v. 19, n. 32, p. 11-20, jul./dez. 2018.

doi: http://dx.doi.org/10.22409/poiesis.1932.11-20

Poiésis, Niterói, v. 19, n. 32, jul./dez. 2018. 


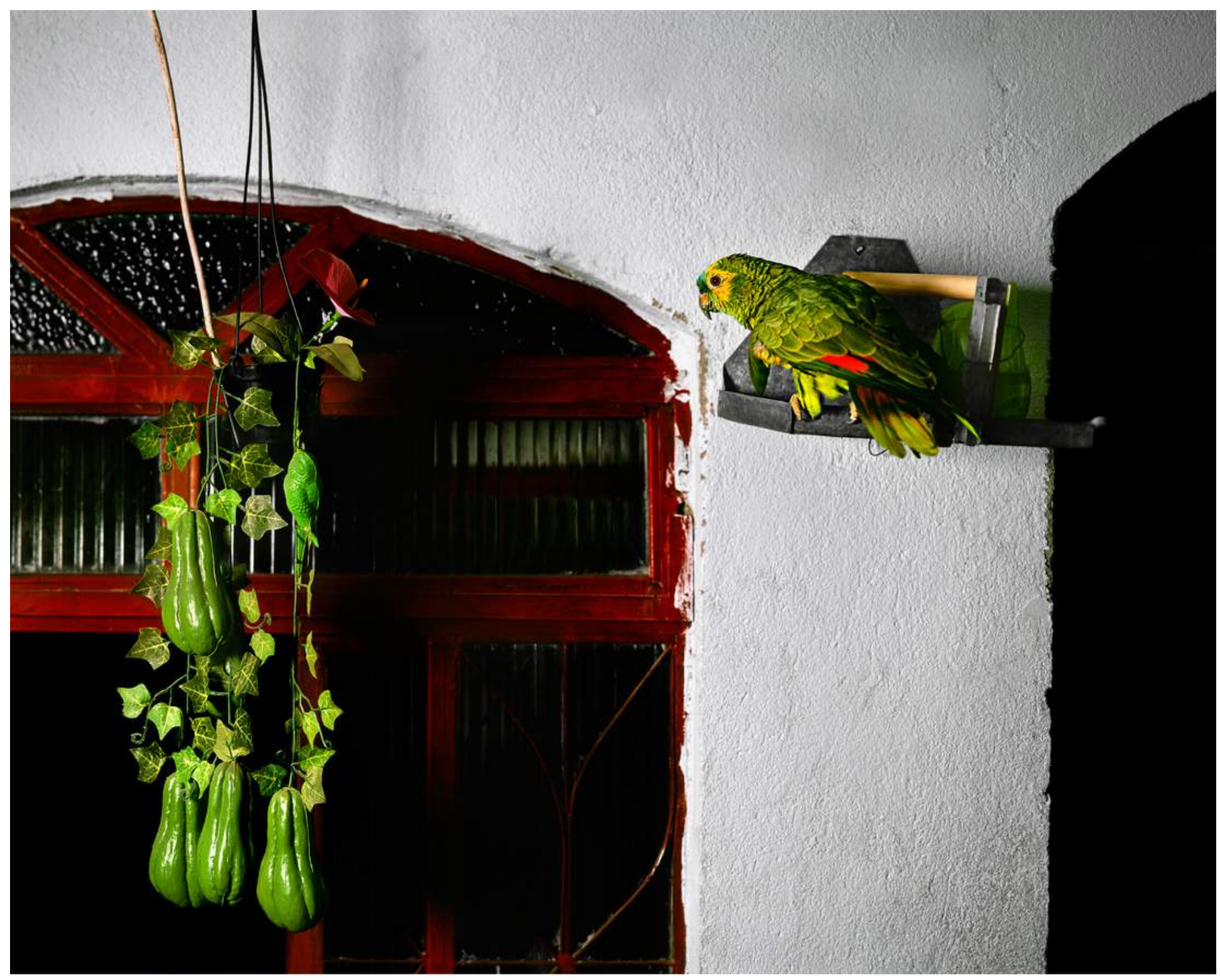




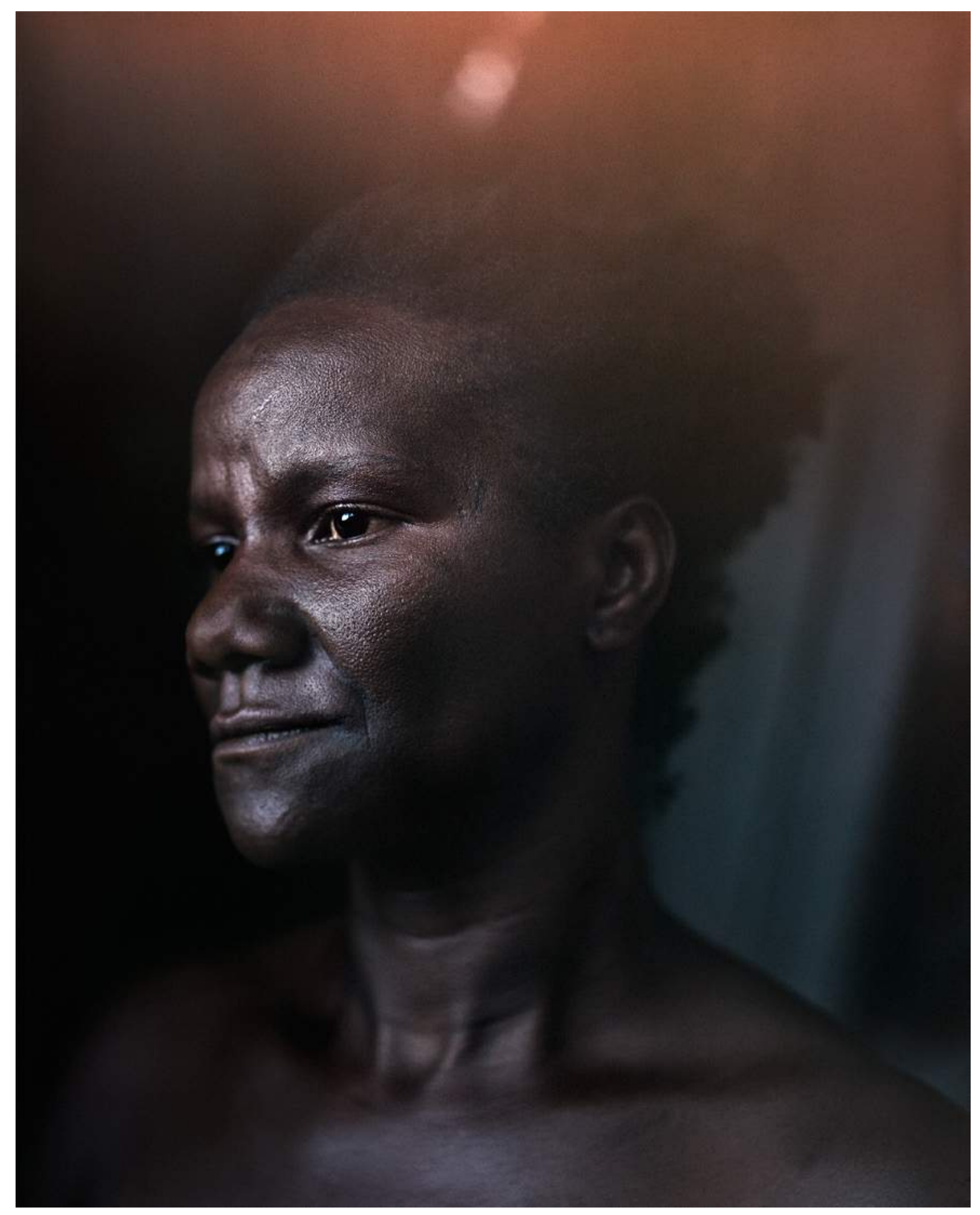




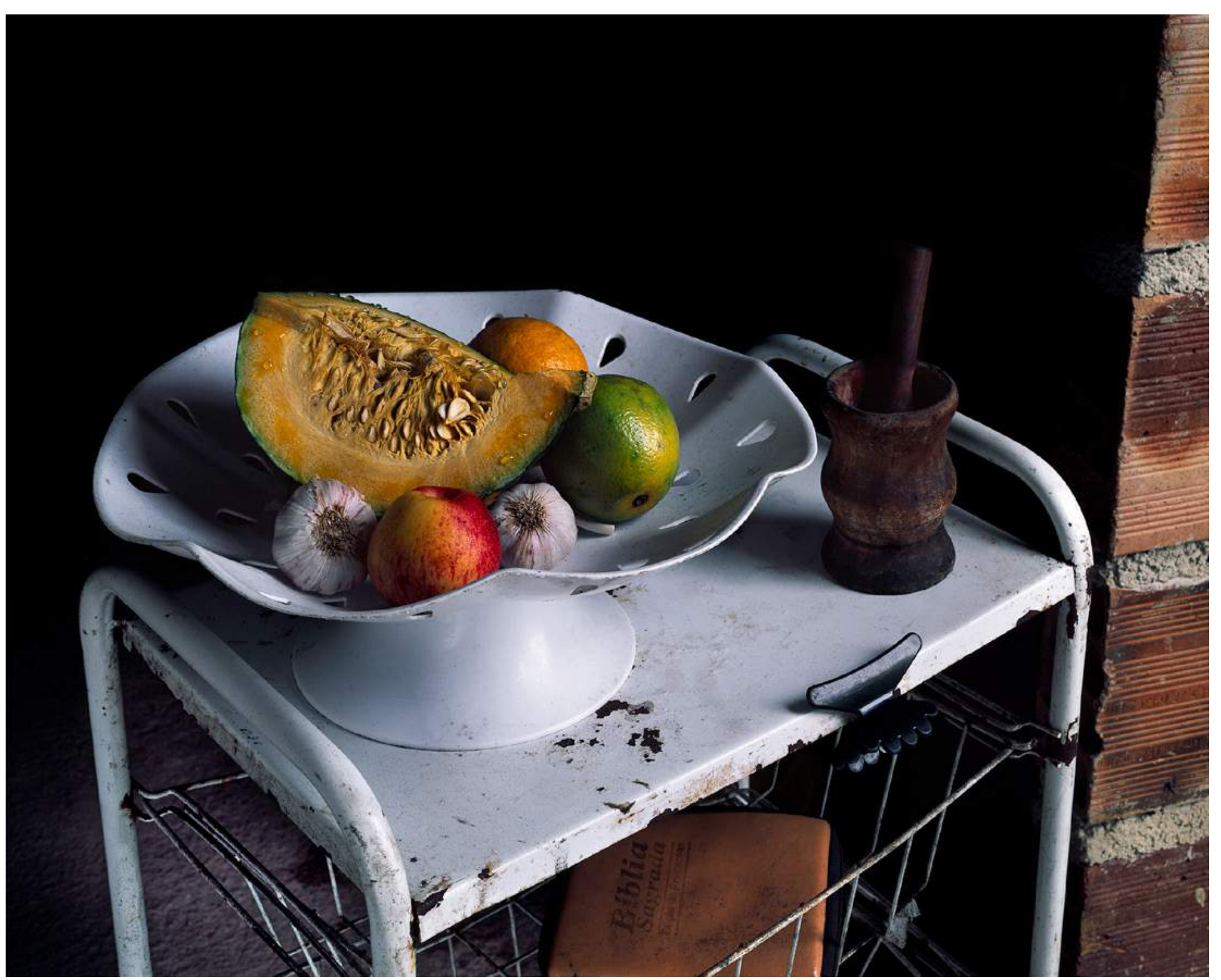




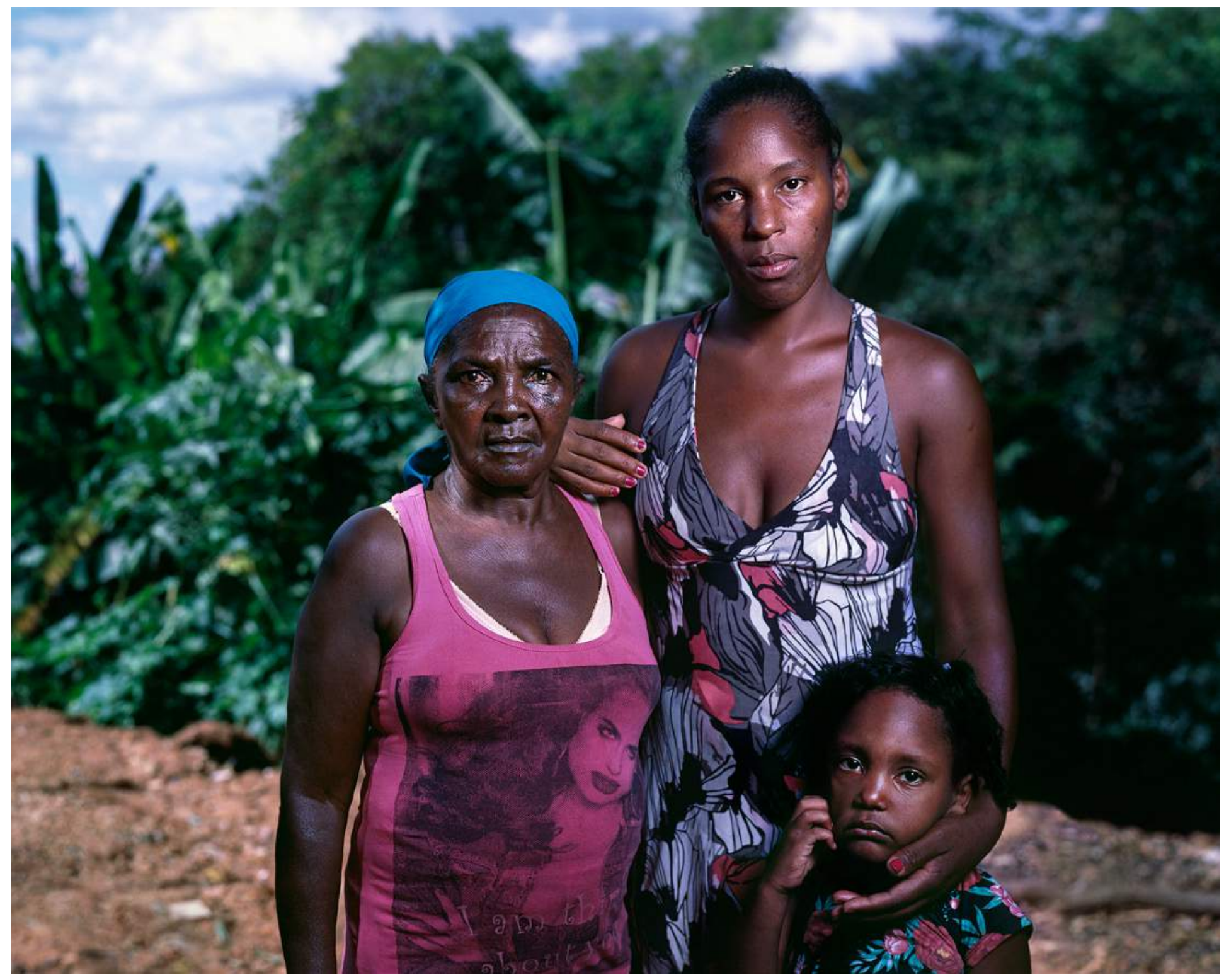




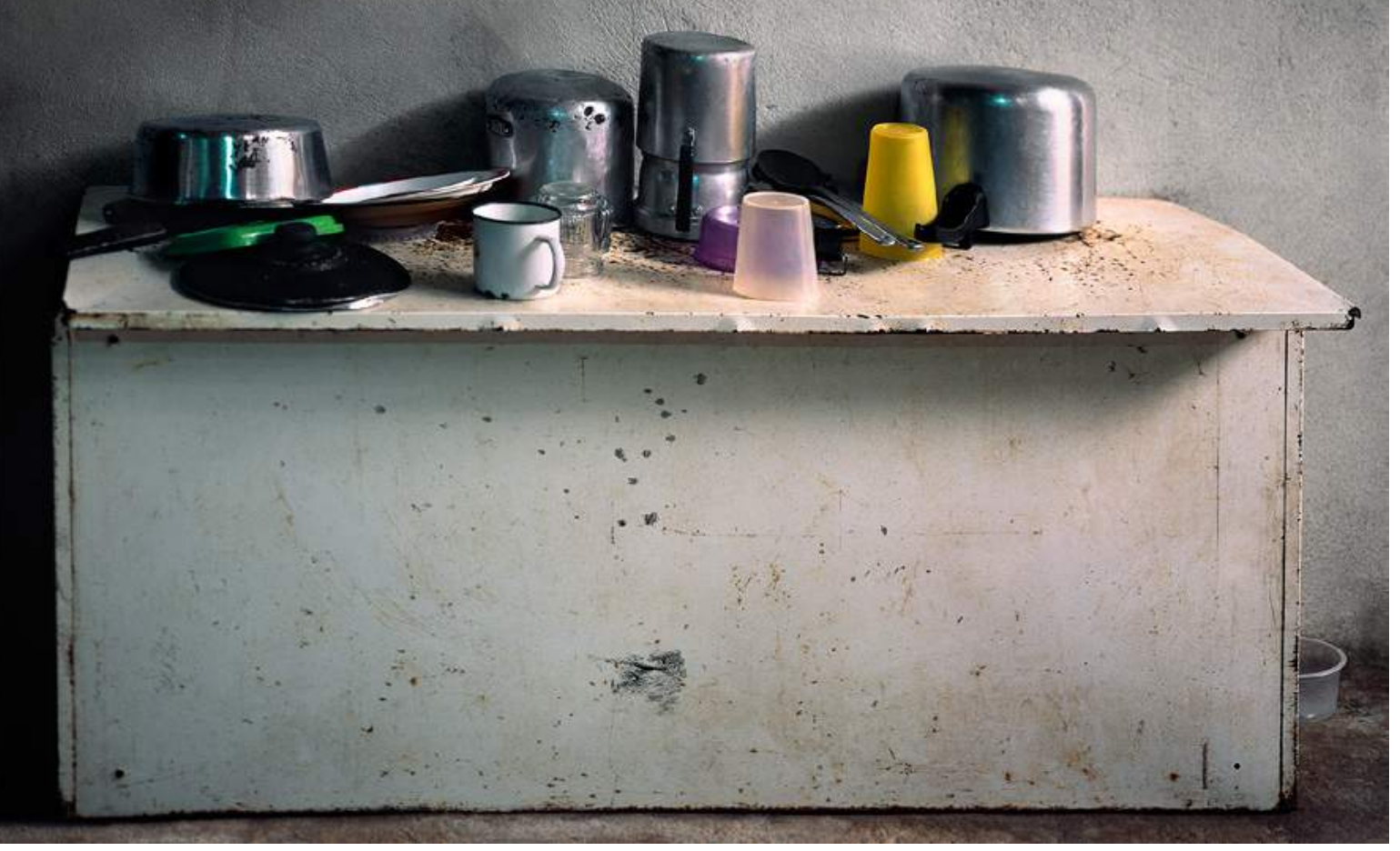




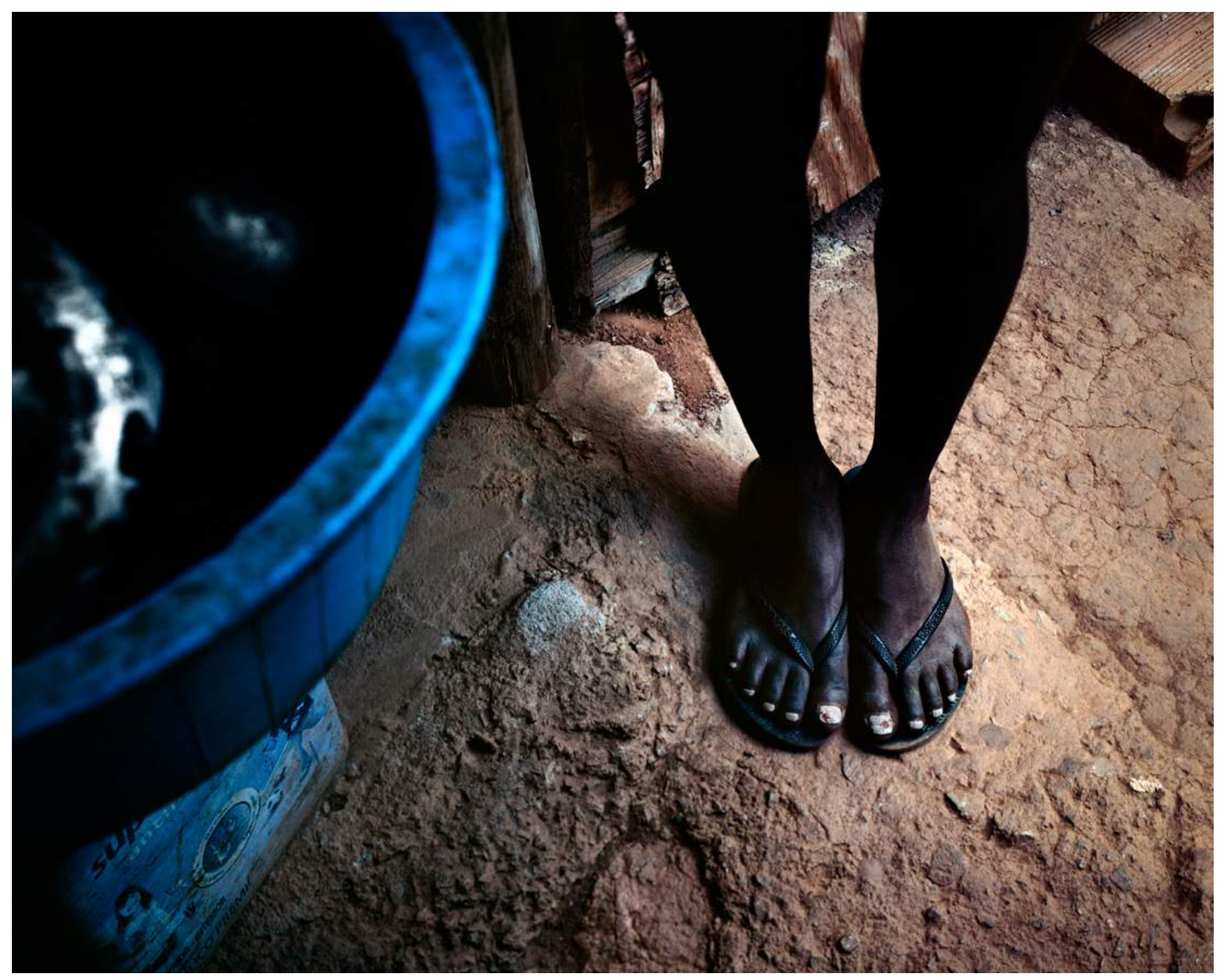




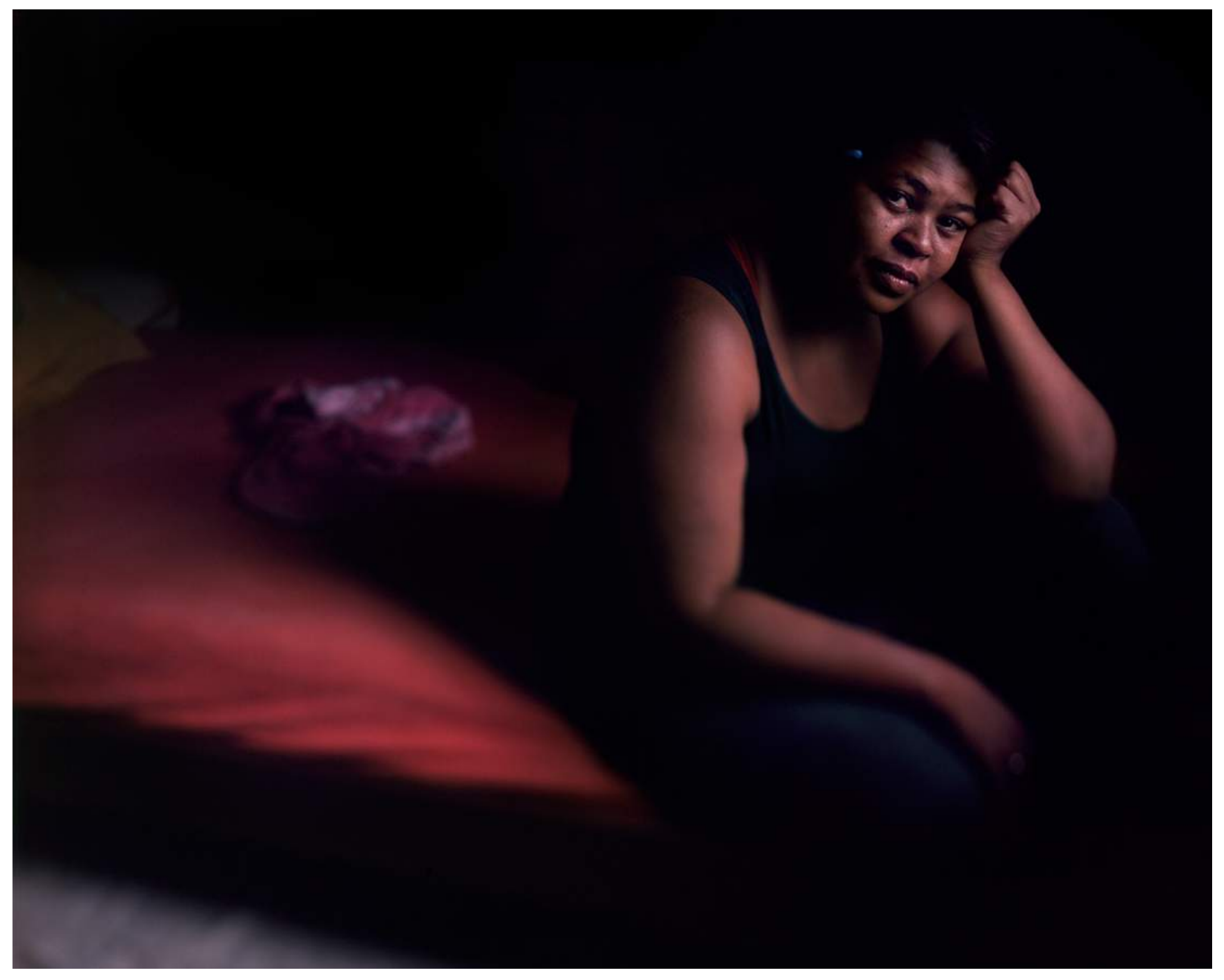




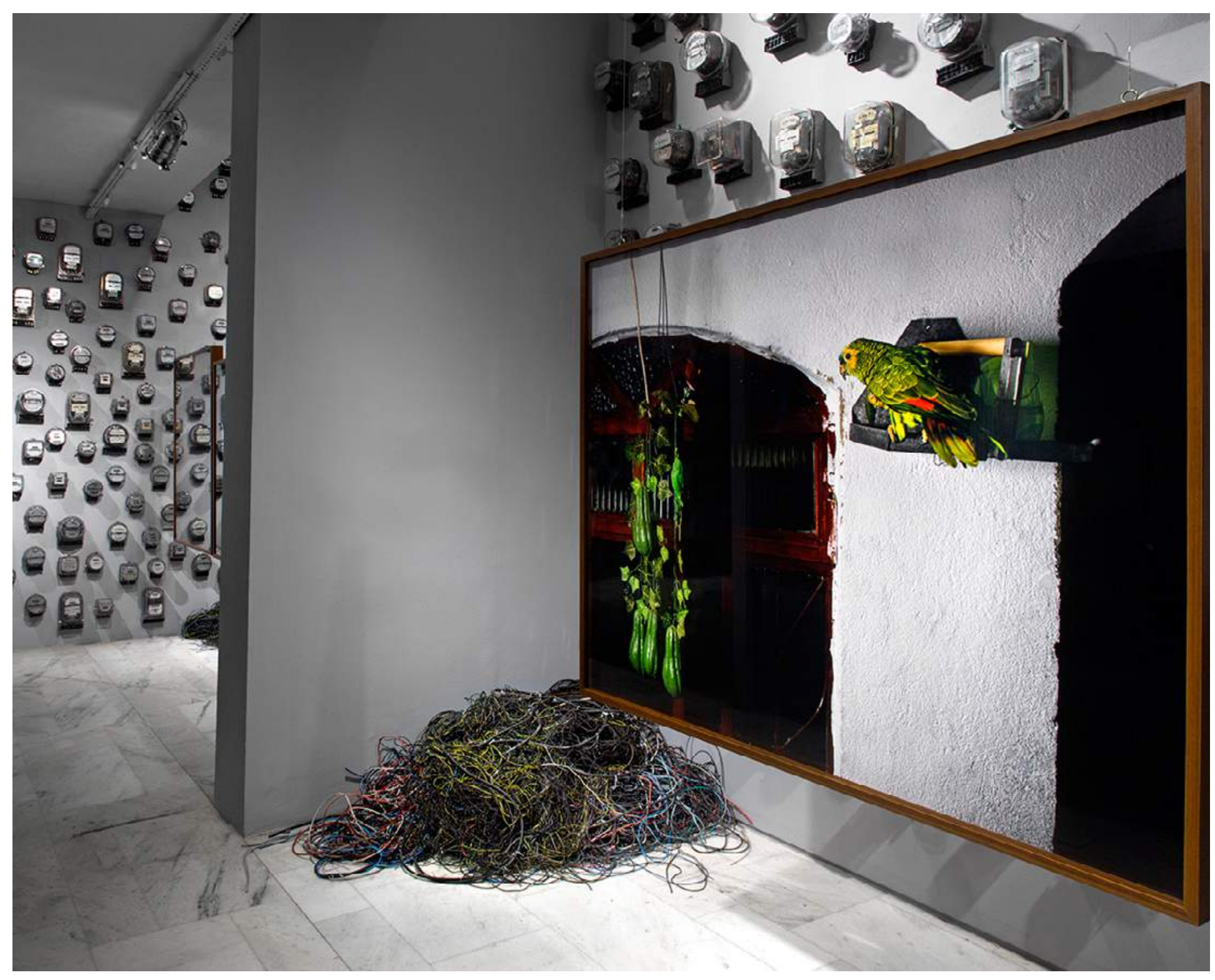

